\title{
Preparation of Fish Scales Hydroxyapatite (FsHAp) for Potential Use as Fillers in Polymer
}

\author{
Alhussein Arkan Majhool ${ }^{1}$, Ismail Zainol ${ }^{1}$, Che Nor Aiza Jaafar ${ }^{2}$, Mustafa Mudhafar ${ }^{1}$, Alsailawi H. A. ${ }^{3}$, Abbas \\ Asaad $^{3}$ and Fouad W. Mezaal ${ }^{1}$ \\ 1. Department of Chemistry, Faculty of Science and Mathematics, Sultan Idris Education University, Tanjong Malim 35900, Perak \\ Darul Ridzuan, Malaysia \\ 2. Department of Mechanical and Manufacturing Engineering, Faculty of Engineering, Universiti Putra Malaysia, Serdang 43400, \\ Selangor, Malaysia \\ 3. Department of Biology, Universiti Pendidikan Sultan Idris (UPSI), Tg Malim, Perak, Malaysia
}

\begin{abstract}
The aims of this study were to prepare natural hydroxyapatite from fish scales (FsHAp) for potential use as a filler in polymer. The FsHAp was prepared from Tilapia fish scales using thermal method. The FsHAp was milled for $48 \mathrm{~h}$ and dried by spray method. The morphology was characterized using field emission scanning electron microscope (FESEM) which showed irregular shape of FsHAp particles with particle size around $7 \mu \mathrm{m}$. The analysis of FsHAp was carried out using Fourier transform infrared spectroscopy (FTIR) and X-ray diffraction (XRD) to confirm chemical structure of FsHAp.
\end{abstract}

Keywords: Hydroxyapatite, polymer, fillers, fish scales.

\section{Introduction}

Hydroxyapatite (HA) is a type of calcium phosphate with a chemical formula of $\mathrm{Ca}_{10}\left(\mathrm{PO}_{4}\right)_{6}(\mathrm{OH})_{2}$ [1-4]. Many studies reported the advantages of hydroxyapatite (HA), especially in stimulating bone healing, and claimed that it has been used in orthopaedics as bone void fillers, dental surgery, orthopaedic and dental implant coating, traumatology, spine and maxillofacial [4-7]. HA is bioactive, non-toxic, non-immunogenic and osteoconductive with a crystallographic structure almost similar to that of the bone mineral [8-10]. However, HA with particle size $<10$ microns is classified as common inorganic filler used to improve the mechanical properties and biocompatibility of polymer composites [11-17], because of its excellent biocompatibility properties[11, 18-22]. It is similar to the silica powder used in polymer composites [23-26].

Corresponding author: Ismail Zainol, professor, Department of Chemistry, Faculty of Science and Mathematics, Sultan Idris Education University.
The application of HA as a filler in epoxy was reported by Oladele et al. [13] and Alhussein et al. [11]. Meanwhile, Scalera et al. [14] prepared epoxy/HA suspensions for stereo lithography in bone tissue engineering and found that the prepared epoxy/HA exhibits good mechanical properties.

A commonly used HA for fillers in the polymer matrix composite is synthetic HA produced from the chemical reaction between ammonium phosphate $\left[\left(\mathrm{NH}_{4}\right)_{2} \mathrm{HPO}_{4}\right]$ and calcium hydroxide $\left[\mathrm{Ca}(\mathrm{OH})_{2}\right]$ [27-30]. It is widely used as a filler in thermoplastic materials, such as high-density polyethylene (HDPE) $[12,31]$. However, synthetic HA is expensive to produce, and its quality is difficult to control. Biological sources of HA, such as fish scales, fish bones, bovine bones, teeth and bones of pig, are alternatives to synthetic HA [2, 32-37]. Fish waste, especially fish scales, is a good source of natural HA because it contains $50 \%$ by weight of scale. Fish scales are also abundant in valuable organic components, such as collagen [38]. The preparation of 
HA from fish scales is biologically safe, economical and biocompatible [36, 39-42]. Jaafar et al. [12] reported the use of natural HA powder (HAp) from fish scales as a filler in HDPE.

\section{Materials and Methods}

Fish scales from tilapia fish were collected from local market at Tanjung Malim, Perak. The fish scales were washed with water to remove dirt. The scales were soaked in hydrochloric acid $(0.2 \mathrm{M})$ for $10 \mathrm{~min}$ to remove fat and other impurities, washed with distilled water and then dried in oven at $80^{\circ} \mathrm{C}$. The fish scales (Fs) were ground into small particles using a grinding machine. The fish scales were loaded into a high-temperature furnace and then heated at $800^{\circ} \mathrm{C}$ for $2 \mathrm{~h}$ and continued at $1,000^{\circ} \mathrm{C}$ for $2 \mathrm{~h}$ to produce fish ash. The fish ash was wet grinded using ball milling

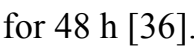

The flow chart for the preparation of FsHAp is shown in Fig. 1. The FsHAp slurry from ball milling was dried to FsHAp powder using spray dryer. The spray dryer apparatus consisted of a high-pressure nozzle that sprays the FsHA slurry in the form of fine mist into the hot air in the chamber. The slurry was evaporated, and the fine FsHA particles were collected in the collector.

The chemical structure of the products was characterized by FT-IR, XRD and the morphology was characterized using field emission scanning electron microscope (FESEM). Meanwhile, the FsHAp particle size was determined using mastersizer 2000 particle size analyser.

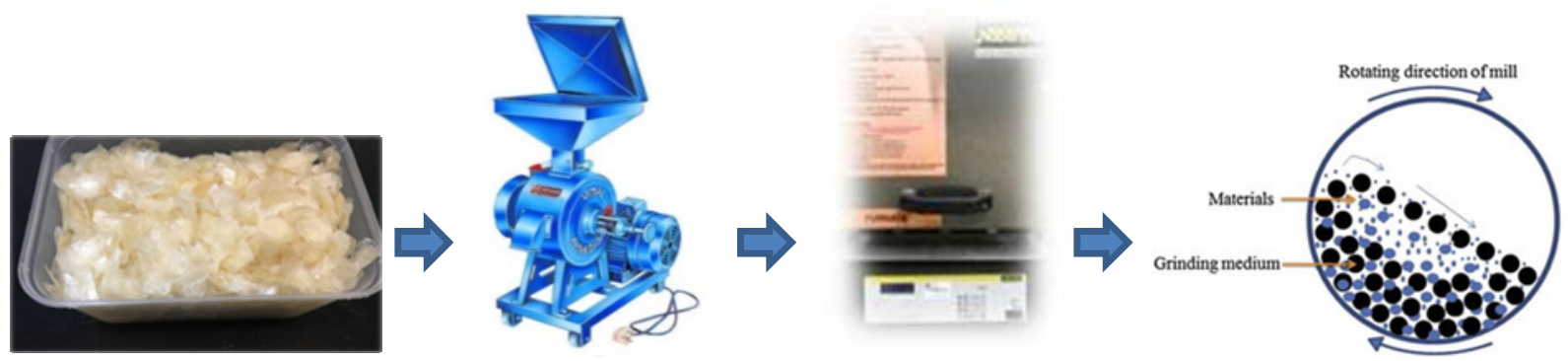

Wash fish scales Grinding of fish scales Calcination at 800 and $1,000{ }^{\circ} \mathrm{C}$ Ball milling for $48 \mathrm{~h}$

FTIRXRD FESEM

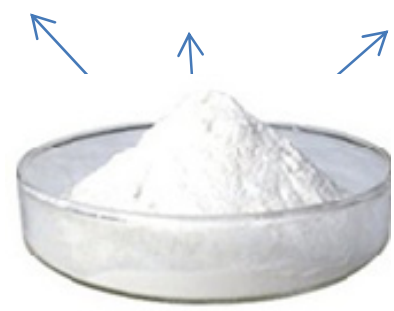

Hydroxyapatite powder

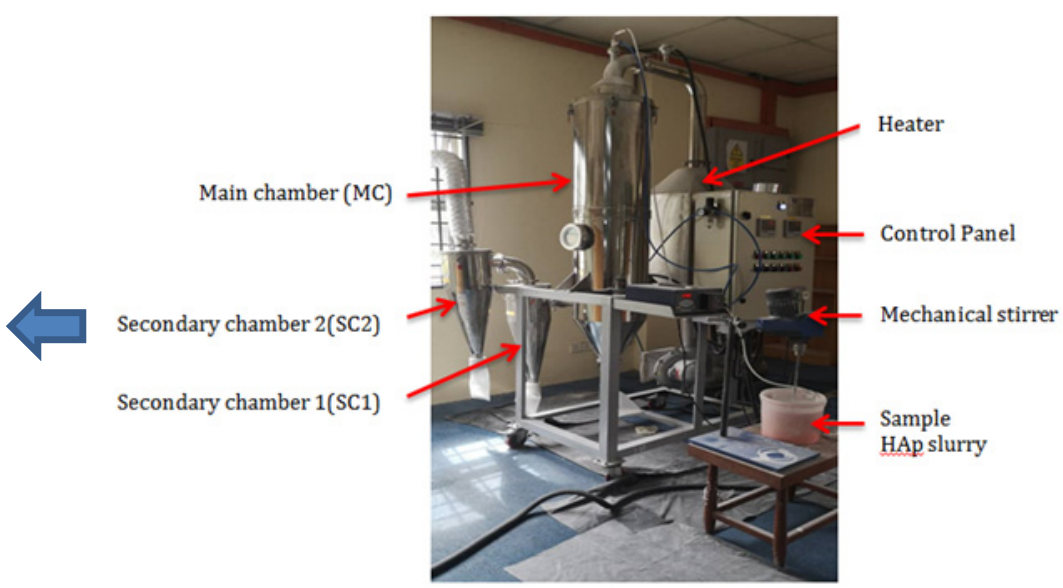

Drying by spray dryer process

Fig. 1 Process flow chart for preparation of natural hydroxyl apatite from fish scales (FsHAp). 


\section{Results and Discussion}

HA from biological sources was prepared because of its biological safety and low cost. Several methods, such as alkaline digestion, enzymatic and direct burning, have been developed to extract HA from fish scales. Direct burning is an easy and cheap way to obtain natural HA. Fish scales are calcination to remove organic component and $\mathrm{HA}$ is retained as ash $[35,43,44]$.

The most common method to dry the hydroxyapatite slurry is thermal drying in which the slurry was heated in an oven for 1 day at $80^{\circ} \mathrm{C}$ to remove water after ball milling. However, oven drying caused the HA fish scale particles to clump to each other, which made them again inseparable to be used as fillers in polymer composites. Thus, this study evaluated the properties of HA fish scale particles prepared by the spray method in which the HA fish scale slurry was not oven dried after ball milling. The spray dry apparatus consisted of a nozzle that sprays the HA fish scale slurry in the form of fine mist into the hot air. The slurry was evaporated and the fine HA fish scale particles were collected in the collector chamber.

\subsection{FTIR Analysis of FsHAp}

Fig. 2 shows the FTIR spectrum of FsHAp. The hydroxyl group $\mathrm{OH}$ showed a sharp peak at around $3,569 \mathrm{~cm}^{-1}$ and a weak peak at $632 \mathrm{~cm}^{-1}$, which corresponded to the stretching mode of hydroxyl group of HA. A broad peak at $1,046 \mathrm{~cm}^{-1}$ showed a single band for the phosphate group, and the peak at $1,091 \mathrm{~cm}^{-1}$ also corresponded to the phosphate group. The bending vibration of $\mathrm{PO}_{4}{ }^{3-}$ was observed in bands located at 560-620 $\mathrm{cm}^{-1}$, and a phosphate band appeared in the region of $472 \mathrm{~cm}^{-1}$ [45]. Typical FTIR spectra can be observed for highly crystalline HA [36, 46-49].

\subsection{XRD Analysis of FsHAp}

The XRD spectrum of FsHAp is shown in Fig. 3. The prominent peaks corresponded to the highly crystalline HA materials [50]. Three main peaks with high intensity were observed in FsHAp at $2 \theta$ values of $31.86^{\circ}, 32.20^{\circ}$ and $33.04^{\circ}$ associated with the planar hkl (211), (300) and (112), respectively. This result is equivalent to the higher peak intensity reported in previous studies [2, 21, 34]. Some low-intensity peaks that appeared in the XRD pattern were associated with the planar hkl (200), (2221), (002), (102), (210), (202), (310), (222), (312), (213), (321), (410) and (004). The spectrum also resembled the standard XRD pattern of HA based on the library collection (ICDD 9-432) [51].

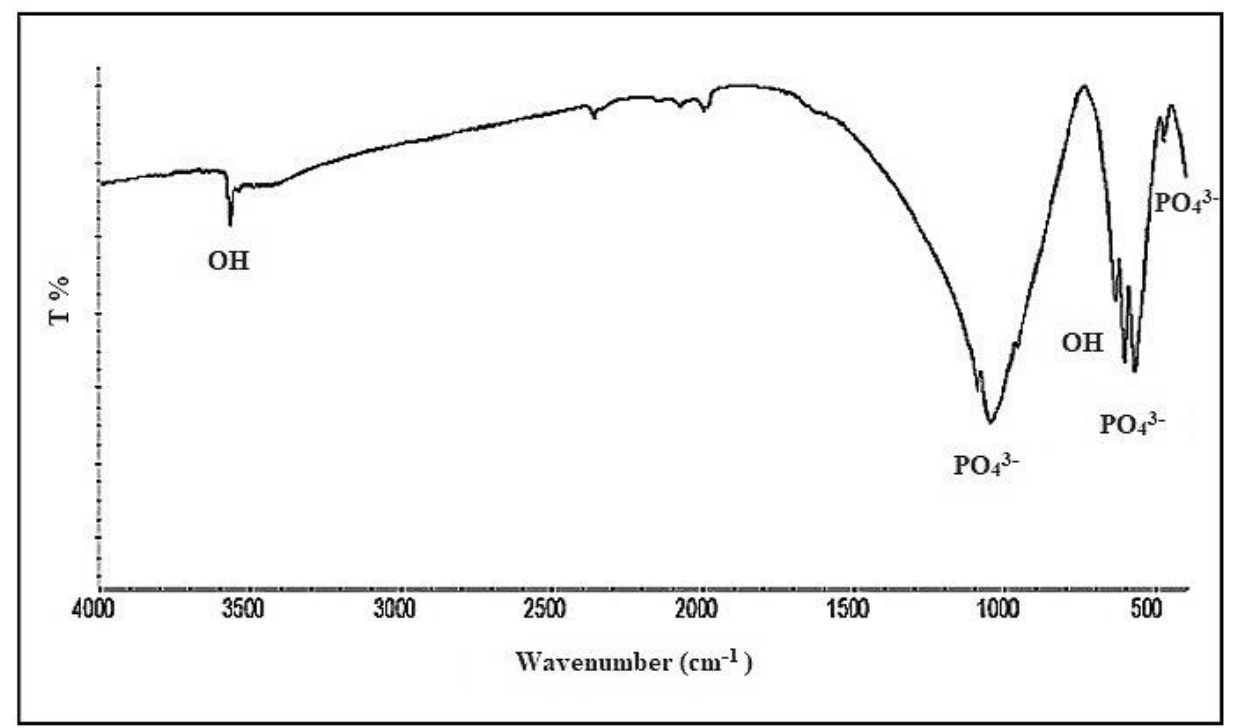

Fig. 2 FTIR spectrum of FsHAp. 


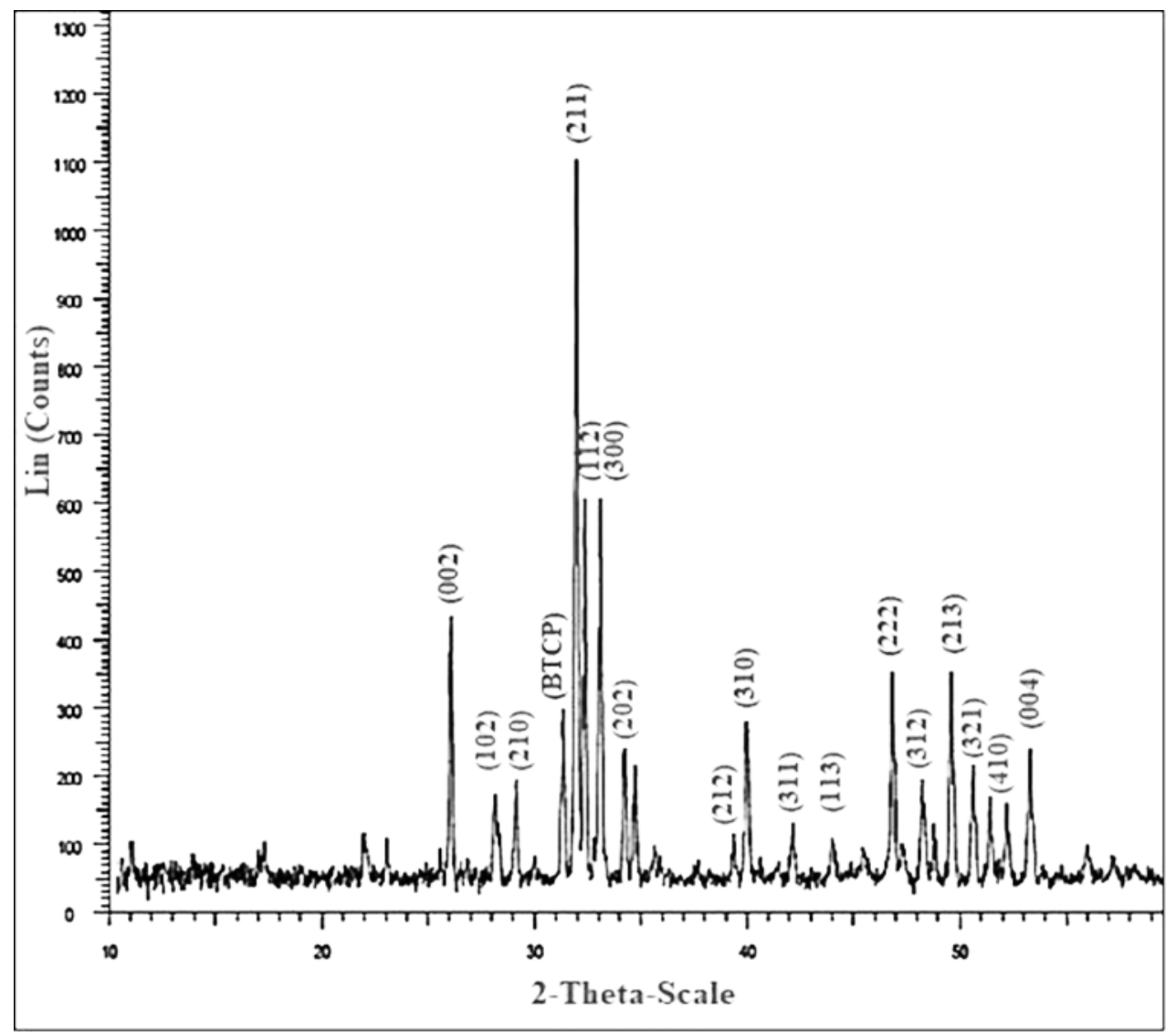

Fig. 3 XRD pattern for FsHAp.

\subsection{Particle Size of FsHAp}

The filler particle size often affects the mechanical properties of composites. Hence the characterization of filler size and their distribution will help to understand the properties of composite. Fig. 4 shows the bimodal distribution of spray dried FsHAp powder used in this research. Overall, filler sizes are fairly distributed, and this contributed toward good dispersion of particles as high amount of small particulate matter is reported to have tendency to agglomerate. Table 1 summarized the particles size results based on $\mathrm{D}_{0.1}, \mathrm{D}_{0.5}$, and $\mathrm{D}_{0.9}$. The results show that $10 \%$ of sample mass $\left(\mathrm{D}_{0.1}\right)$ comprised of particles with diameter below $0.810 \mu \mathrm{m}$ and $90 \%$ of sample mass $\left(\mathrm{D}_{0.9}\right)$ with particle size below $23.343 \mu \mathrm{m}$. The median particle size $\left(\mathrm{D}_{0.5}\right)$ comprised of $50 \%$ mass particles with particle size of $5.180 \mu \mathrm{m}$. The median particle size $5.180 \mu \mathrm{m}$ is taken as FsHAp particle size. This particle size is within the as fillers in HDPE composite [12].

\subsection{FESEM Analysis of FsHAp}

The morphology of FsHAp was investigated by SEM, and the results are presented in Fig. 5. The results show irregular shape of FsHAp particles with some degree of agglomeration due to static force between particles. However, for synthetic HAp, the particles are more spherical or doughnut shapes as reported by Monmaturapoj et al. [32]. The SEM micrograph shows the mixture of particle size of FsHAp with particle size around 7 microns.

EDX analysis (Fig. 6) was performed to determine the $\mathrm{Ca} / \mathrm{P}$ ratio of the sample. This analysis was performed to confirm the type of $\mathrm{HA}$ obtained after thermal heating at $1,200^{\circ} \mathrm{C}$. The calculated $\mathrm{Ca} / \mathrm{P}$ ratio for the FsHAp powder was 1.67 , according to the chemical formula of the standard $\mathrm{HA}[30]$, the calcium-to-phosphoromolar ratio is approximately 1.67 . 


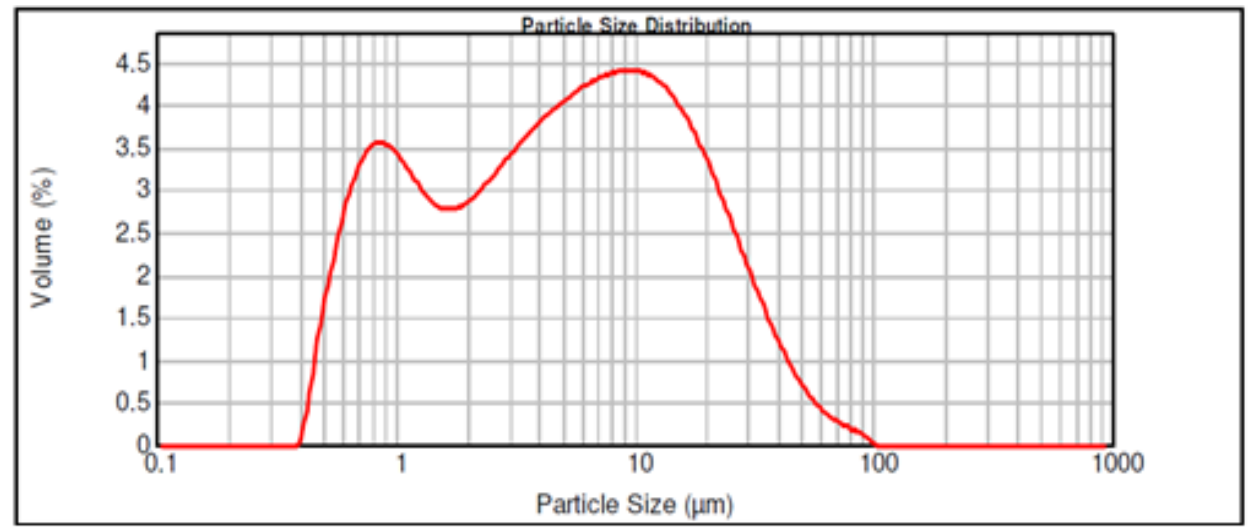

Fig. 4 Particle size distribution of FsHAp.

Table 1 FsHAp particle properties.

\begin{tabular}{lllll}
\hline Particle size $(\mu \mathrm{m})$ & & & & \\
\hline Sample & $\mathrm{D}_{0.5}$ & $\mathrm{D}_{0.1}$ & $\mathrm{D}_{0.99}$ & Surface $\operatorname{area}\left(\mathrm{m}^{2} / \mathrm{g}\right)$ \\
FsHAp & 5.180 & 0.810 & 23.343 & \\
\hline
\end{tabular}

$\mathrm{D}_{0.5}$ : median particle size; $\mathrm{D}_{0.1}$ and $\mathrm{D}_{0.9}$ : the size below which $10 \%$ and $90 \%$ of the particle diameter lie, respectively.

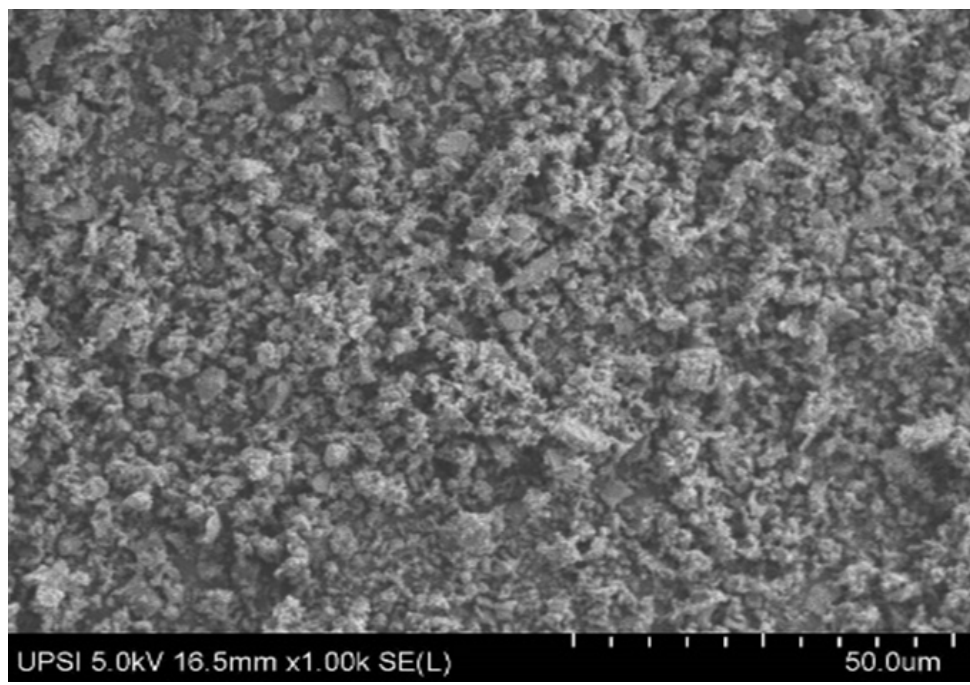

Fig. 5 Scanning electron micrograph for FsHAp.

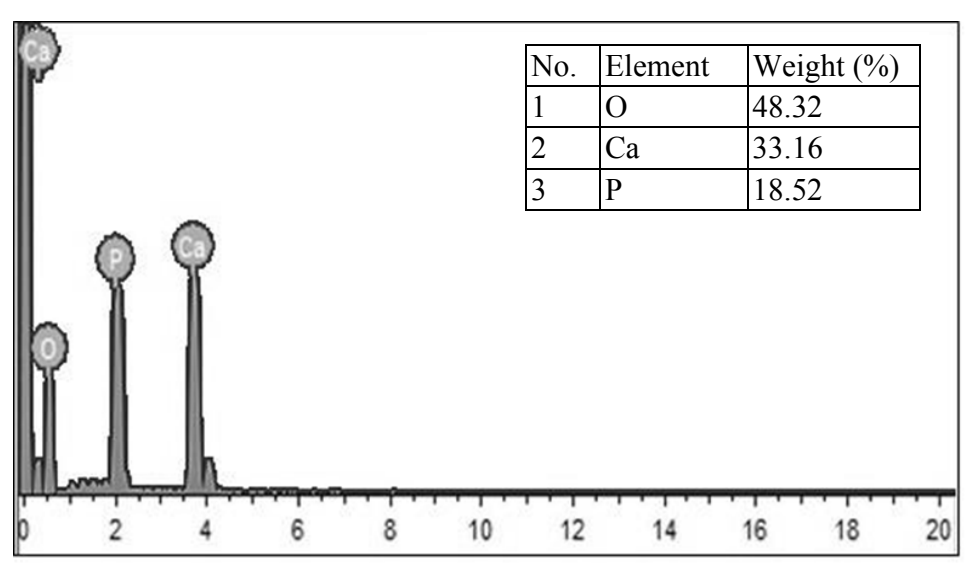

Fig. 6 EDX spectrum of FsHAp. 


\section{Conclusion}

Hydroxyapatite was successfully produced from fish scales using thermal method. The FsHAp with particle size below $10 \mu \mathrm{m}$ is classified as fillers in polymer. The chemical structure of FsHAp was confirmed using FT-IR and XRD analysis.

\section{References}

[1] Mondal, S., Bardhan, R., Mondal, B., Dey, A., Mukhopadhyay, S. S., Roy, S., Guha, R., and Roy, K. 2012. "Synthesis, Characterization and in Vitro Cytotoxicity Assessment of Hydroxyapatite from Different Bioresources for Tissue.” Bulletin of Materials Science 35 (4): 683-91.

[2] Fara,A. N. K. A., and Abdullah, H. Z.2015. "Characterization of Derived Natural Hydroxyapatite (HAp) Obtained from Different Types of Tilapia Fish Bones andScales" AIP Conf. Proc., vol. 020077.

[3] Mondal, S., Mondal, B., Dey, A., and Mukhopadhyay, S. S. 2012. "Studies on Processing and Characterization of Hydroxyapatite Biomaterials from Different Bio Wastes." J. Miner. Mater. Charact. Eng. 11 (1): 55-67.

[4] Wibisono, Y. 2018. "Communication Synthesis and Sinterability of Hydroxyapatite from Fishery By-Products.” J. Korean Ceram. Soc. 55 (6): 6-9.

[5] Mondal, S., Mahata,S., Kundu, S., and Mondal, B. 2010. "Processing of Natural Resourced Hydroxyapatite Ceramics from Fish Scale." British Ceramic Transactions 109 (4): 234-9.

[6] Gao, C., Zhao, K., Lin, L., Wang, J., Liu, Y., and Zhu, P. 2019. "Preparation and Characterization of Biomimetic Hydroxyapatite Nanocrystals by Using Partially Hydrolyzed Keratin as Template Agent." Nanomaterials 9 (2).

[7] Pon-on, W., Suntornsaratoon, P., Charoenphandhu, N., and Thongbunchoo, J. 2016. "Hydroxyapatite from Fish Scale for Potential Use as Bone Scaffold or Regenerative Material." Mater. Sci. Eng. C 62: 183-9.

[8] Pu, N. A. S. M., Koshy, P., Abdullah, H. Z., Idris, M. I., and Lee, T. C. 2019. "Syntheses of Hydroxyapatite from Natural Sources." Heliyon 3: e01588.

[9] Bone, S. F. 2015. "Isolation and Characterization of Nano-Hydroxyapatite from Salmon Fish Bone." Materials 8 (8): 5426-39.

[10] Hasan Ali, A., and Rosmilah, M. 2019. "Effects of Food Processing on the Stability and Quality of Shellfish Allergens." J. US-China Med. Sci. 16: 149-63.

[11] Majhool, A. A., Zainol, I., Azziz, S. S. S. A., and Jaafar, C. A. N. 2019. "Mechanical Properties Improvement of
Epoxy Composites by Natural Hydroxyapatite from Fish Scales as a Fillers." Int. J. Res. Pharm. Sci. 10 (2): 1424-9.

[12] Jaafar, C. N. A., Zainol, I., and Amin, M. M. 2017. "Fish Scales Hydroxyapatite as Potential Fillers in HDPE Composites for Bone Replacement Applications." Solid State Phenom. 264: 79-82.

[13] Oladele, I. O., Akinola, O. S., Agbabiaka, O. G., and Omotoyinbo, J. A. 2018. "Mathematical Model for the Prediction of Impact Energy of Organic Material Based Hydroxyapatite (HAp) Reinforced Epoxy Composites." Fibers Polym. 19 (2): 452-9.

[14] Scalera, F., Esposito Corcione, C., Montagna, F., Sannino, A., and Maffezzoli, A. 2014. "Development and Characterization of UV Curable Epoxy/Hydroxyapatite Suspensions for Stereolithography Applied to Bone Tissue Engineering." Ceram. Int. 40 (10): 15455-62.

[15] Monmaturapoj, N. 2017. "Properties of Poly(Lactic Acid)/Hydroxyapatite Composite through the Use of Epoxy Functional Compatibilizers for Biomedical Application.” J. Biomater. Appl. 32 (2): 175-90.

[16] Šupova, M. 2009. "Problem of Hydroxyapatite Dispersion in Polymer Matrices: A Review." Journal of Materials Science Materials in Medicine 20 (6): 1201-13.

[17] Lee, H. J., Kim, S. E., Choi, H. W., Kim, C. W., Kim, K. J., and Lee, S. C. 2007. "The Effect of Surface-Modified Nano-Hydroxyapatite on Biocompatibility of Poly( $\varepsilon$-Caprolactone)/Hydroxyapatite Nanocomposites." Eur. Polym. J. 43 (5): 1602-8.

[18] Miranda, M., Esteban-Tejeda, L., and Malpartida, F. 2010. "Silver-Hydroxyapatite Nanocomposites as Bactericidal and Fungicidal Materials." International Journal of Materials Research 101 (1): 122-7.

[19] Sadat-shojai, M., Atai, M., Nodehi, A., and Nasiri, L. 2010. "Hydroxyapatite Nanorods as Novel Fillers for Improving the Properties of Dental Adhesives: Synthesis and Application." Dent. Mater. 26 (5): 471-82.

[20] Wang, J., and Shaw, L. L. 2009. "Biomaterials Nanocrystalline Hydroxyapatite with Simultaneous Enhancements in Hardness and Toughness." Biomaterials 30 (34): 6565-72.

[21] Zhu, Y., Xu, L., Liu, C., Zhang, C. and Wu, N. 2018. "Nucleation and Growth of Hydroxyapatite Nanocrystals by Hydrothermal Method Nucleation and Growth of Hydroxyapatite Nanocrystals by Hydrothermal Method." AIP Advances 8 (8): 085221.

[22] Andrea, P. 2018. "Comparative Study between Natural and Synthetic Hydroxyapatite: Structural, Morphological and Bioactivity Properties."Matéria 23 (4).

[23] Series, C. 2018. "Effect of Silica Fillers on Mechanical Properties of Epoxy/Kenaf Composites Effect of Silica Fillers on Mechanical Properties of Epoxy/Kenaf Composites.” J. Phys. Conf., pp. 3-9. 
[24] Ahmad, T., and Mamat, O. 2013. "Studying the Effects of Adding Silica Sand Nanoparticles on Epoxy Based Composites." Journal of Nanoparticles 2013: 1-5.

[25] Liu, Y., Hsu, C., Wei, W., and Jeng, R. 2003. "Preparation and Thermal Properties of Epoxy-Silica Nanocomposites from Nanoscale Colloidal Silica." Polymer 44: 5159-67.

[26] Chen, L., Chai, S., Liu, K., Ning, N., Gao, J., and Liu, Q., et al. 2012. "Enhanced Epoxy/Silica Composites Mechanical Properties by Introducing Graphene Oxide to the Interface." ACS Appl. Mater. Interface 4 (8): 4398-404.

[27] Cai, Y., Mei, D., Jiang, T., and Yao, J. 2010. "Synthesis of Oriented Hydroxyapatite Crystals: Effect of Reaction Conditions in the Presence or Absence of Silk Sericin." Mater. Lett. 64 (24): 2676-8.

[28] Chen, J., Wang, Y., Chen, X., Ren, L., Lai, C., He, W. and Zhang, Q. 2011. “A Simple Sol-Gel Technique for Synthesis of Nanostructured Hydroxyapatite, Tricalcium Phosphate and Biphasic Powders." Mater. Lett. 65 (12): 1923-6.

[29] Guo, X., Yan, H., Zhao, S., Zhang, L., Li, Y., and Liang, X. 2013. "Effect of Calcining Temperature on Particle Size of Hydroxyapatite Synthesized by Solid-State Reaction at Room Temperature." Advanced Powder Technology 24 (6):1034-8.

[30] Taylor, P., Al Qasas, N. S., and Rohani, S. 2007. "Synthesis of Pure Hydroxyapatite and the Effect of Synthesis Conditions on its Yield, Crystallinity, Morphology and Mean Particle Size." Separation Science and Technology 40 (15): 3187-224.

[31] Parra, C., Gonzalez, G., and Albano, C. 2009. "Synthesis and Characterization of Composite Materials HDPE/HA and PMMA/HA Prepared by Sonochemistry." Macromol. Symp. 286 (10): 60-9.

[32] Kamalanathan, P. 2014. "Development of Hydroxyapatite from Natural Fish Bone through Heat Treatment." Trends in Biomaterials \& Artificial Organs 20 (1): 20-3.

[33] Mahmud, M. H., Salam, K. A., Gafur, M. A., Rana, A. A., Qadir, M. R., Masum, S. M., Sarker, M. and Karim, M. M. 2015. "Chemical Characteristics of Hydroxyapatite from Oyster Shell by Thermo-Chemical Process." Int. J. Innov. Res. Sci. Eng. Technol. 4 (7): 5039-47.

[34] Granito, R. N., Renno, A. C. M., Yamamura, H., de Almeida, M. C., Ruiz, P. L. M. and Ribeiro, D. A. 2018. "Hydroxyapatite from Fish for Bone Tissue Engineering: A Promising Approach." Int J Mol Cell Med. 7 (2): 80-90.

[35] Bahrololoom, M. E., Javidi, M., Javadpour, S., and Ma, J. 2009. "Characterisation of Natural Hydroxyapatite Extracted from Bovine Cortical Bone Ash.” J. Ceram. Proc. Res.10 (2): 129-38.

[36] Zainon, I., Alwi, N. M., Abidin,M. Z., Haniza, H. M. Z., Ahmad, M. S., and Ramli, A. 2012. "Physicochemical Properties of Hydroxyapatite Extracted from Fish Scales."
Adv. Mater. Res. 545: 235-9.

[37] Adenan, N. H., Zainol, N. A. R. I., and Jaafar, C. N. A. 2018. "Extraction of Nanohydroxyapatite from Waste Bovine Bone Using Alkaline Digestion Method.” J. Phys. Conf. Ser.

[38] Sankar, S., Sekar, S., Mohan, R., Rani, S., Sundaraseelan, J., and Sastry, T. P. 2008. "Preparation and Partial Characterization of Collagen Sheet from Fish (Lates calcarifer) Scales." International Journal of Biological Macromolecules 42 (1): 6-9.

[39] Tao, J., Jiang, W., Pan, H., Xu, X., and R. T. Ã. 2007. "Preparation of Large-Sized Hydroxyapatite Single Crystals Using Homogeneous Releasing Controls." $J$. Cryst. Growth 308: 151-8.

[40] Tan, D. X., Xu, B., Zhou, X., and Reiter, R. J. 2018. "Associated Health Consequences and Rejuvenation of the Pineal Gland." Molecules 23 (2): 301.

[41] Shi, P., Liu, M., Fan, F., Yu, C., Lu, W., and Du, M. 2018. "Characterization and Biocompatibility with Osteoblasts of Natural Hydroxyapatite Originated from Fish Bone." Materials Science and Engineering: C 90: 706-12.

[42] Nath, N., and Krishna, P. 2013. "Extraction and Characterization of Biocompatible Hydroxyapatite from Fresh Water Fish Scales for Tissue Engineering Scaffold.” Bioprocess and Biosystems Engineering 37 (3): 433-40.

[43] Bano, N., Jikan, S. S., Basri, H., Adzila, S., Bakar, S. A., and Nuhu, A. H. 2017. "Natural Hydroxyapatite Extracted from Bovine Bone.”J. Sci. Technol. 9 (2): 22-8.

[44] Ramli, R. A., Adnan, R., Bakar, M. A., and Masudi, S. M. 2011. "Synthesis and Characterisation of Pure Nanoporous Hydroxyapatite." J. Phys. Sci. 22 (1): 25-37.

[45] Arsad, M. S. M., Lee, P. M., and Lee, K. H. 2011. "Synthesis and Characterization of Hydroxyapatite Nanoparticles and $\beta$-TCP Particles." Int. Conf. Biotechnol. Food Sci. 7: 184-8.

[46] Azis, Y., Jamarun, N., Arief, S., and Nur, H. 2015. "Facile Synthesis of Hydroxyapatite Particles from Cockle Shells (Anadaragranosa) by Hydrothermal Method." Oriental Journal of Chemistry 31 (2): 1099-105.

[47] Chandrasekar, A., Sagadevan, S., and Dakshnamoorthy, A. 2013. "Synthesis and Characterization of Nano-Hydroxyapatite (n-HAP ) Using the Wet Chemical Technique." International Journal of Physical Sciences 8 (32): 1639-45.

[48] Ghahremani, D., Mobasherpour, I., Manafi, S., and Keramatpour, L. 2013. "Potential of Nano Crystalline Calcium Hydroxyapatite for Tin(II) Removal from Aqueous Solutions: Equilibria and Kinetic Processes." Arab. J. Chem. 10 (1): S461-71.

[49] Analyst, T., and Mcmahon, G. 2008. "Detection of Calcium Phosphate Crystals in the Joint Fluid of Patients with Osteoarthritis - Analytical Approaches and 
Challenges." Analyst 133 (3): 302-18.

[50] Zhang, G., Chen, J., Yang, S., Yu, Q., Wang, Z., and Zhang, Q. 2011. "Preparation of Amino-Acid-Regulated Hydroxyapatite Particles by Hydrothermal Method."
Mater. Lett. 65 (3): 572-4.

[51] Shahabi, S. 2014. "Effect of Gamma Irradiation on Structural and Biological Properties of a PLGA-PEG-Hydroxyapatite Composite." Sci. World J. 